ISSN 0103-8478

\title{
Nanotubos de carbono: potencial de uso em medicina veterinária
}

\author{
Carbon nanotubes: potential use in veterinary medicine \\ Ingrid Rios Lima Machado $^{I^{*}}$ Heloisa Maria Falcão Mendes ${ }^{I}$ \\ Geraldo Eleno Silveira Alves ${ }^{I}$ Rafael Resende Faleiros $^{\mathrm{I}}$
}

\section{- REVISÃo BIBLIOGRÁFICA -}

RESUMO

A utilização de nanomateriais em sistemas de segurança alimentar, detecção de patógenos, proteção de ambientes, no diagnóstico e tratamento de doenças, como sistema de entrega de fármacos e na bioengenharia tecidual tem contribuído para os avanços alcançados na ciência animal. Suas propriedades físicas, químicas e mecânicas, além de seu grande potencial de associação com outros materiais contribuem para sua aplicação em diferentes campos da medicina veterinária, por exemplo, como biomarcadores, onde as propriedades eletrônicas e ópticas possibilitam a transdução de sinais, na terapia fototérmica, devido à habilidade em converter a luz infravermelha (LIV) em calor, na engenharia tecidual, graças à resistência mecânica, flexibilidade, elasticidade e baixa densidade, além de muitas outras possíveis aplicações. O objetivo deste trabalho é informar sobre conceitos, propriedades e aplicações dos NTCs, destacando sua aplicabilidade nas áreas biomédicas, com destaque para setores da medicina veterinária que já se utilizam desse material.

Palavras-chave: entrega de fármacos, biosensores, terapia fototérmica, engenharia tecidual.

\section{ABSTRACT}

The use of nanomaterials in systems of food safety, pathogen detection, protection environments, diagnosis and treatment of diseases such as drug delivery system and tissue engineering has contributed to advances in animal science. Carbon nanotubes are an example, their use has been highlighted in different biological areas. Their physical, chemical and mechanical properties as well as its great potential for combination with other materials contribute to its application in different fields of veterinary medicine, for example, as biomarkers, where the electronic and optical properties enable signal transduction, in photothermal therapy due the ability to convert infrared light (LIV) into heat, in tissue engineering due to mechanical strength, flexibility, elasticity, low density, and many other possible applications. The objective of this review is to present the CNTs and the main areas of animal science that surpass in the study of this material.

Key words: drug delivery, biosensors, photothemal therapy, tissue engineering.

\section{INTRODUÇÃO}

Nos últimos anos, tem-se conhecido inovações proporcionadas pela nanotecnologia que abrangem da medicina à eletrônica. Esta ciência tem sido usada na medicina veterinária nos sistemas de segurança alimentar, detecção de patógenos, proteção de ambientes, no diagnóstico e tratamento de doenças e como sistema de entrega de fármacos (SCOTT, 2007). Vários materiais têm sido trabalhados em escala nanométria, dentre eles, destacam-se os nanotubos de carbono (NTCs), definidos como átomos de carbono arranjados em anéis aromáticos condensados, formados por lençóis de grafeno enrolados em cilindros (IIJIMA, 1991). Um lençol de grafeno é uma estrutura bidimensional, composta por uma rede de átomos carbono dispostos em forma hexagonal e unidos entre si por hibridização de órbitas de seus elétrons (Figura 1A). De acordo com o número de camadas de grafeno, os NTCs podem ser classificados em nanotubos de carbono de parede simples, constituída de uma camada de grafeno (Figura 1B); ou de múltiplas camadas de grafeno concêntricas (Figura 1C) (HADDON, 2002).

Apesar das inúmeras possibilidades de uso dessa nova tecnologia na área da saúde, pouco ainda

\footnotetext{
IDepartamento de clínica e cirurgia veterinárias, Universidade Federal de Minas Gerais (UFMG), 31270-901, Belo Horizonte, MG, Brasil.

E-mail: ingridvetgyn@gmail.com.*Autor para correspondência. 
a

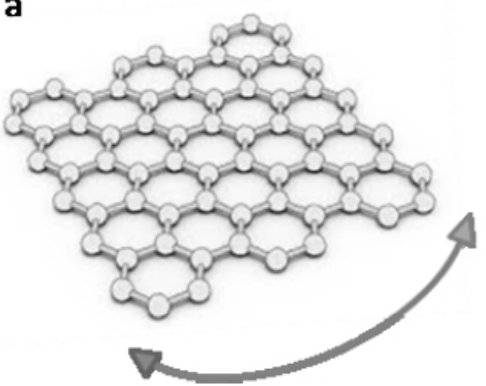

b

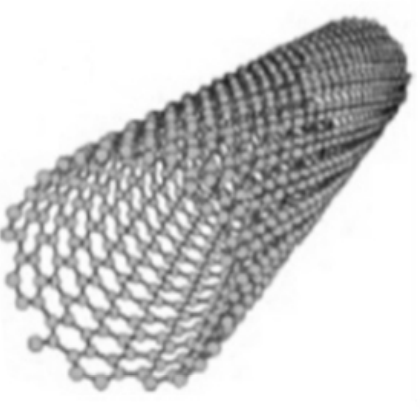

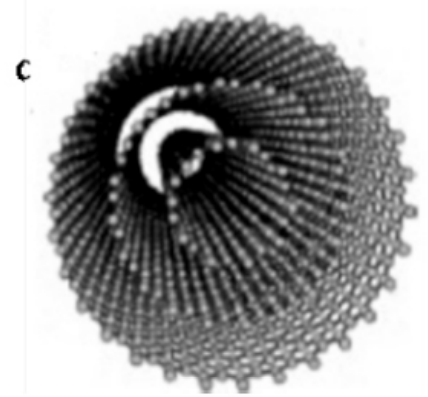

Figura 1 - (a) Lençol de grafeno sendo enrolado em forma de cilindro. (b) Nanotubos de carbono de parede simples. (c) Nanotubos de carbono de paredes múltiplas.

se sabe a respeito dos NTCs. As pesquisas, em sua grande maioria, se restringem a estudos in vitro e à utilização em animais de laboratório. Nesse último aspecto, a medicina veterinária tem contribuído para descoberta de novos processos e tratamentos que, futuramente, com mais estudos, poderão ser aplicados em diversas espécies, como também na medicina humana. O objetivo desta revisão é descrever os NTCs, suas formas de funcionalização e aplicação, assim como as principais áreas da veterinária que se destacam no estudo desse material.

\section{Propriedades físicas}

Os NTCs pertencem à família dos fulerenos, ou seja, à terceira forma alotrópica do carbono, juntamente com o grafite e o diamante. Sua principal vantagem tecnológica é a resistência mecânica (BERHANU et al., 2009). Além das propriedades eletrônicas, mecânicas e químicas únicas, é possível associá-lo a outros materiais, melhorando tais propriedades e inserindo-lhes novas características (SAITO et al., 2009; BIANCO et al., 2011).

Uma propriedade que torna os NTCs bastante atrativos é o diâmetro em nanoescala, que acarreta numa vasta superfície em relação ao seu volume. Essa grande razão área/volume é desejada, pois permite que os NTCs sejam usados como carreadores de biomoléculas, ou seja, moléculas que possam interagir com as células e tecidos (MÉNARDMOYON et al., 2010). Além disso, os NTCs têm uma absorbância óptica elevada na região infravermelha do comprimento de onda, permitindo que sejam visualizados por meio de imagens de microscopia infravermelha fluorescente. NTCs também podem agir como absorvedores de microondas, permitindo a liberação de fármacos baseadas nesse mecanismo (VEETIL \&YE, 2009).

Funcionalização dos nanotubos de carbono

Uma etapa importante para viabilizar o uso dos NTCs é a adição de grupos químicos funcionais à sua estrutura química. Esse processo, denominado de funcionalização, é fundamental, pois os NTCs, em seu estado original, são completamente insolúveis na maioria dos solventes orgânicos e meios aquosos (BIANCO et al., 2011). Além da solubilização, a funcionalização traz outras vantagens para as pesquisas biológicas, estando estas relacionadas à capacidade de translocação através de membranas celulares e à redução de efeitos citotóxicos (KOSTARELOS et al., 2007).

Uso na medicina veterinária

O uso dos nanotubos de carbono têm se destacado em diferentes setores da medicina veterinária. Sua utilização como biosensores apresenta grande potencial nas áreas de produção animal e inspeção sanitária (BRANDÃO et al., 2011). Por exemplo, a detecção de resíduos e contaminantes em produtos de origem animal ainda é um desafio. A identificação de patógenos como Salmonella por meio da adição de anticorpos específicos nas paredes laterais dos NTCs demostrou que esse método é capaz de identificar a bactéria de forma mais rápida e específica que os métodos convencionais (LERNER et al., 2011). A identificação de compostos organofosforados e antibióticos do grupo $\beta$ - lactâmicos também é possível por meio da funcionalização de NTC (BALASUBRAMANIAN \& BURGHARD, 2006). Apesar dos avanços alcançados com as pesquisas, a aplicação dos NTC encontra- 
se na fase de estudo e ainda não tem condições de ser amplamente empregado (KUZMA, 2010). Das possíveis aplicações dos NTC na medicina veterinária, o campo da saúde é o que tem apresentado maiores avanços (Tabela 1).

Aplicação como biosensores

Os NTCs têm se mostrado de alta aplicabilidade para uso como biosensores. Suas propriedades eletrônicas e ópticas intrínsecas possibilitam a transdução dos sinais. Sua estrutura física, incluindo grande superfície de área e propriedade semicondutora permite a mensuração, detecção ou adsorção de interações biomoleculares ao longo das paredes laterais dos NTCs. A proximidade de cargas ou biomoléculas polarizadas produz efeitos de propagação sobre NTCs isolados ou dispostos em redes, gerando um efeito de campo transitório que, por sua vez, possibilita a quantificação do grau de ligação específico ou não para biomoléculas (LIU et al., 2009).

Os NTCs de parede simples, graças a suas propriedades semicondutoras, têm sido propostos como sensores químicos para moléculas gasosas como $\mathrm{NO}_{2}$ ou NH $\mathrm{NH}_{3}$ (KONG et al., 2000). Sua funcionalização com cadeias de óxido de polietileno não só melhora as ligações não específicas das proteínas com os NTCs, mas também permite a ligação de proteínas de interesse específico, através da conjugação de seus receptores aos NTCs funcionalizados, podendo assim ser detectadas eletronicamente sem necessidade de marcação (CHEN et al., 2003). Sendo assim, a aplicação desses sistemas tem potencial para a identificação clínica de biomoléculas, como exemplo, anticorpos associados às doenças autoimunes, o que torna os NTCs uma importante ferramenta de diagnóstico (BOCZKOWSKI \& LANONE, 2007).

Sistema de entrega de fármacos

Outra forma de aplicação dos NTCs é como vetor para distribuição de fármaco. Esse sistema pode ajudar a resolver problemas de transporte de componentes farmacológicos importantes que precisam ser internalizados e, por essa razão, podem encontrar potenciais terapêuticos de aplicação (BOCZKOWSKI \& LANONE, 2007). Alguns fatores influenciam no desenvolvimento dos sistemas de entrega de fármaco, como, por exemplo, eficiência dos métodos de entrega, preservação da bioatividade molecular do fármaco e reforço na cinética de carreamento e liberação dos fármacos em seus alvos (MADANI et al., 2013).

O mecanismo exato pelo qual os NTCs penetram nas células ainda é motivo de especulação. A internalização celular pode variar de acordo com a funcionalização, tamanho, forma e grau de dispersão (KAM et al., 2006; MADANI et al., 2011). Duas rotas principais foram descritas na literatura, sendo elas: endocitose, na qual NTCs funcionalizados com proteínas ou DNA são internalizados de forma ativa, ou seja, dependente de energia (KAM et al., 2006) e difusão passiva, na qual a funcionalização dos NTCs faz com que sua solubilização aumente, sendo possível sua internalização de forma passiva (BIANCO et al., 2005; KOSTARELOS et al., 2007).

NTCs têm sido usados para carrear cargas biológicas que variam desde pequenas moléculas de fármacos a biomacromoléculas, como proteínas, DNA e RNA, em diferentes tipos de células. Tais macromoléculas não são capazes de difusão nas células e raramente atravessam as membranas celulares por conta própria. A distribuição intracelular dessas moléculas, geralmente, tem como objetivo aplicações terapêuticas (KAM \& DAI, 2005). Acredita-se que NTCs com comprimento até 400nm são internalizados por difusão passiva e que aqueles maiores que 400nm são internalizados por endocitose (ANTONELLI et al., 2010). Além disso, os NTCs que se ligam a proteínas como albumina bovina, estreptavidina e outras são internalizadas via endocitose, enquanto os NTCs que se ligam a moléculas menores como amônia, anfotericina B e outras são internalizados via difusão passiva (MADANI et al., 2011).

Vários mecanismos têm sido usados para conjugar moléculas aos NTCs, dentre eles, métodos covalentes para moléculas pequenas e métodos não covalentes para moléculas com cadeias

Tabela 1 - Principais aplicações dos nanotubos de carbono na medicina veterinária.

Principais aplicações dos NTCs na medicina veterinária

\begin{tabular}{ll}
\hline Aplicação & Atuação \\
Biosensores & Identificação de patógenos e contaminantes \\
Terapia fototermal & Tratamento de câncer \\
Sistema de entrega de fármacos & Transporte de componentes farmacológicos a locais específicos \\
Engenharia tecidual & Biomaterial na regeneração tecidual \\
\hline
\end{tabular}

Ciência Rural, v.44, n.10, out, 2014. 
aromáticas. Um exemplo de sucesso envolvendo tais moléculas é a doxorubicina, fármaco comumente usado no tratamento quimioterápico do câncer. Esse fármaco pode ser carregado na superfície de NTCs, funcionalizados especificamente, para esse tipo de transporte, por meio de uma ligação de cargas (LIU et al., 2007). Essa ligação entre NTCs/moléculas é dependente do $\mathrm{pH}$ e favorece a liberação do fármaco no endossomo e lisossomo, assim como no micro ambiente do tumor, com pH ácido (LIU et al., 2009).

Além da conjugação e do transporte de fármacos na superfície externa dos NTCs, sua estrutura oca permite a encapsulamento de moléculas dentro deles. Embora algumas pesquisas abordem a inserção de biomoléculas dentro dos NTCs (HILDER \& HILL, 2008), a distribuição de fármacos por esse mecanismo foi reportada raramente (LIU et al., 2009).

Os NTCs de parede múltipla possuem maior potencial para aplicação como sistemas de entrega de fármacos, devido ao maior diâmetro interno, quando comparado aos NTCs de parede simples. Isso permite maior capacidade de carreamento. Além disso, a estabilidade química e mecânica permite o transporte de fármacos em diversos ambientes (MADANI et al., 2013). Apesar disso, há vários relatos sobre o uso de NTCs de parede simples para esse propósito. Já se demonstrou que o uso de NTCs de parede simples conjugado a fármacos anticancerígenos possuem tempo de circulação maior na corrente sanguínea do que os fármacos não conjugados, o que pode levar a uma melhor e mais prolongada absorção dos fármacos pelas células tumorais, melhorando o efeito de permeabilidade e retenção do fármaco (MADANI et al., 2011).

A melhora nos mecanismos de distribuição dos NTCs no citosol celular pode levar à obtenção de sistema de entrega de fármacos mais eficiente e, por fim, no desenvolvimento de novas terapias e diagnósticos (ANTONELLI et al., 2010).

\section{Terapia fototérmica}

O desenvolvimento de terapias alvo tem resultado em perspectiva de novas abordagens no tratamento do câncer. Conceitualmente, um fármaco alvo representa uma molécula responsiva que se liga a um carreador, com afinidade específica para receptores de proteínas, localizados na membrana celular. Esses receptores específicos, portados pelo carreador, são capazes de se concentrar apenas na área biológica desejada (IANCU \& MOCAN, 2011).

Neste campo, as pesquisas para alvos seletivos tumorais com NTCs biofuncionalizados têm sido exploradas intensamente, devido à sua habilidade em converter a luz infravermelha (LIV) em calor. O uso desta técnica é particularmente atrativo, pois os tecidos vivos não absorvem essa energia (CHAKRAVARTY et al., 2008). Embora os sistemas biológicos sejam transparentes para LIV, a força intrínseca de absorbância dos NTCs pode ser usada, nesse caso, para estimulação óptica destes dentro das células vivas (BOCZKOWSKI \& LANONE, 2007). A transmissão optoeletrônica nas estruturas de grafite dos NTCs gera uma energia térmica que rapidamente se difunde, causando necrose celular (XU et al., 2010). Além da capacidade de conversão da LIV em calor, a hipertermia também aumenta a permeabilidade vascular do tumor, e assim a distribuição de fármacos nas regiões tumorais. O carreamento pelos NTCs de moléculas alvo biológicas como anticorpos, DNA, polietileno-glicol e fatores de crescimento tem sido proposto com uma forma de tratamento para tumores (CHAKRAVARTY et al., 2008).

Os NTCs de parede múltipla são preferidos para terapias fototérmicas em relação aos NTCs de parede simples, pela maior capacidade de liberar energia quando exposto a LIV. Isso ocorre pelo maior número de elétrons por partícula e também de tubos metálicos, o que leva à absorção da LIV em uma taxa mais alta (MADANI et al., 2011).

Apesar do grande potencial do uso dos NTCs na terapia fototérmica e dos avanços alcançados em sua utilização como moléculas bioativas, ainda há muito que pesquisar. Vários estudos têm sido conduzidos, contudo, ainda existem limitações quanto à internalização seletiva de nanoconjugações pelas células cancerígenas. Isso se explica pela presença de receptores usados para ligações das moléculas alvo na membrana de células não cancerígenas, embora em concentração menor que nas células cancerígenas (IANCU et al., 2011).

O principal desafio para se transformar os NTCs em moléculas alvo é torná-los solúveis e estáveis sem perder a especificidade da porção de direcionamento e capacidade térmica (CHAKRAVARTY et al., 2008).

\section{Engenharia tecidual}

Os NTCs têm mostrado grande potencial de uso na área de engenharia tecidual pelas particularidades quando há resistência mecânica, flexibilidade, elasticidade e baixa densidade. Além disso, os NTCs também podem ser incorporados em outros materiais estruturais, promovendo reforço estrutural ou conferindo novas propriedades, como condução elétrica, que pode auxiliar diretamente no crescimento celular (VEETIL \& YE, 2009). 
Os NTCs têm sido explorados para o restabelecimento de uma variedade de tecidos, dentre eles destacam-se tecidos ósseos. Várias pesquisas já foram realizadas reportando a influência dos NTCs em células osteoblásticas cultivadas in vitro (SAITO et al., 2009). Por exemplo, células cultivadas em membranas de policarbonato revestidas com NTCs apresentaram propriedades e arquitetura favoráveis à multiplicação e ao funcionamento celular. Além disso, a atividade da fosfatase alcalina (ALP), um marcador usado para avaliação da formação de células osteoblásticas, foi maior quando comparadas aos grupos não tratados com NTCs (AOKI et al., 2007). Também se verificou, em culturas de fibroblastos e osteoblastos, alto grau de viabilidade das células em contato com os NTCs, que apresentaram rápida síntese de colágeno tipo I e ausência de citocina pró-inflamatória IL-6, de radicais livres e manutenção das concentrações de osteocalcina (CHOLPEK et al., 2006).

Estudos in vitro mostraram que NTCs de parede múltipla, não modificados quimicamente, promoveram formação óssea por meio de sua interação com osteoblastos (SHIMIZU et al., 2012). Os autores atribuíram a aceleração na diferenciação de osteoblastos ao acúmulo de cálcio promovido pelos NTCs de parede múltipla. Aparentemente, a presença dos NTCs aumenta a concentração de cálcio e essa, quando detectada por osteoblastos indiferenciados, faz esses se diferenciarem em osteoblastos maduros, promovendo a calcificação. A absorção de cálcio pelos NTCs de parede múltipla é atribuída ao seu potencial negativo, que atrai os íons de cálcio (YAMAMOTO et al., 2008).

Outra hipótese é que a aceleração na maturação dos osteoblastos estaria relacionada à capacidade dos NTCs em adsorver proteínas. Essa capacidade é atribuída à sua estrutura específica e extensa área de superfície, além das propriedades eletrônicas e catalíticas. Pela área de superfície maior, a quantidade de fatores de crescimento absorvida é maior e consequentemente o recrutamento e ativação celular (LI et al., 2009).

Resultados promissores, demonstrando biocompatibilidade, osteointegração e osteocondução, ou seja, condições fundamentais para o uso dos NTCs como implantes ósseos, também têm sido demonstrados em estudos in vivo. A exemplo, partículas de NTCs de parede múltipla aderiram diretamente em defeitos tibiais induzidos em ratos, e se integraram à matriz óssea, sem interferir no reparo ósseo e se tornando integradas ao tecido ósseo (USUI et al., 2008). Em coelhos, uma mistura de propileno e NTCs de parede múltipla foi usada para preencher defeito no côndilo do fêmur. As análises de microtomografia mostraram que, após 12 semanas, a formação óssea no defeito preenchido com esse material foi maior que nos outros grupos, sendo de $200 \%$ maior que no grupo preenchido apenas com propileno. Histologicamente, no mesmo espaço de tempo, observou-se diferença na reposta óssea do grupo tratado com NTCs quando comparado aos outros grupos (SITHARAMAN et al., 2008).

Os resultados relacionados à segurança do uso de NTCs ainda são controversos. Os diferentes tipos de funcionalização, assim como as diferentes concentrações usadas, dificultam a padronização dos resultados e sua interpretação. Apesar de poucos estudos in vivo, os resultados são favoráveis ao uso dos NTCs. Entretanto, mais estudos são necessários para determinar a segurança e o sucesso, como implante ósseo, principalmente no que se refere a possíveis efeitos da permanência desse material durante maior tempo no corpo, já que, na maioria dos estudos realizados, o período de análise não passou de 90 dias. Outra especulação tem sido em relação aos efeitos citotóxicos dos NTCs. Estudos recentes em farmacocinética mostraram que a dispersão de NTCs por diferentes procedimentos podem levar a efeitos tóxicos não específicos (FIRME \& BANDARU, 2010). Entretanto, essa citotoxicidade está relacionada a doses altas de NTCs. Por isso, uma solução proposta é a utilização de doses menores de NTCs, para minimizar os efeitos citotóxicos (IANCU et al., 2011). Adicionalmente, a funcionalização da superfície dos NTCs com grupos químicos específicos, ou espécies biológicas, pode ser uma alternativa viável para o desenvolvimento de sua biocompatibilidade e consequentemente uma solução para sua citotoxicidade (LIU et al., 2009).

\section{CONCLUSÃO}

Os estudos na área de nanotecnologia têm contribuído com rápidos avanços no tratamento de diversas patologias, entretanto, a reatividade dos NTCs com os sistemas biológicos ainda não foi completamente esclarecida. As diversas formas de produção, purificação e funcionalização, assim como as diferentes concentrações, geram resultados contraditórios, o que dificulta a interpretação de resultados e conclusões. Mais estudos se fazem necessários para garantir funcionalidade e segurança na utilização dos NTCs na Veterinária

\section{REFERÊNCIAS}

ANTONELLI, A. et al. Improved cellular uptake of functionalized single-walled carbon nanotubes. Nanotechnology, v.21, n.42, 
p.425101-425115, 2010. Disponível em: <http://iopscience.iop. org/0957-4484/21/42/425101>.. Acesso em: 21 jan. 2013. doi: $10.1088 / 0957-4484 / 21 / 42 / 425101$.

AOKI, N. et al. Carbon nanotubes as scaffolds for cell culture and effect on cellular functions. Dental Materials Journal, v.26, n.2, p.178-185, 2007. Disponível em: <https://www.jstage.jst.go.jp/ article/dmj/26/2/26_2_178/_article>. Acesso em: 23 fev. 2013. doi: $10.4012 / \mathrm{dmj} .26 .178$.

BALASUBRAMANIAN, K.; BURGAHARD, M. Biosensors based on carbono nanotubes. Analytical and Bionalytical Chemistry, v.385, n.3, p.452-468, 2006. Disponível em: <http:// link.springer.com/article/10.1007/s00216-006-0314-8>. Acesso em: 26 nov. 2013. doi: 10.1007/s00216-006-0314-8.

BERHANU, D. et al. Characterization of carbon nanotubes in the context of toxicity studies. Environmental Health: A Global Access Science Source, v.8, Suppl.1, p.S3, 2009. Disponível em: <http://www.ncbi.nlm.nih.gov/pmc/articles/PMC2796499/>. Acesso em: 15 jan. 2013. doi: 10.1186/1476-069X-8-S1-S3.

BIANCO, A. et al. Biomedical applications of functionalised carbon nanotubes. Chemical Communication, v.41, n.5, p.557680, 2005. Disponível em: <http://pubs.rsc.org/en/Content/ ArticleLanding/2005/CC/b410943k\#!divAbstract>. Acesso em: 27 jan. 2013. doi: 10.1039/B410943K.

BIANCO, A. et al. Making carbon nanotubes biocompatible and biodegradable. Chemical communications, v.47, n.37, p.1018310188, 2011. Disponível em: <http://pubs.rsc.org/en/Content/ ArticleLanding/2011/CC/c1cc13011k\#!divAbstract>. Acesso em: 18 jan. 2013. doi: 10.1039/C1CC13011K.

BOCZKOWSKI, J.; LANONE, S. Potential uses of carbon nanotubes in the medical field: how worried should patients be? Nanomedicine, v.2, n.4, p.407-410, 2007. Disponível em: <http:// www.futuremedicine.com/doi/abs/10.2217/17435889.2.4.407? url_ver=Z39.88-2003\&rfr_id=ori:rid:crossref.org\&rfr_dat $=\mathrm{cr}$ pub\%3dwww.ncbi.nlm.nih.gov\&>. Acesso em: 20 jan. 2013. doi: 10.2217/17435889.2.4.407.

BRANDÃO, H.M. et al. Nanotecnologia: a próxima revolução da agropecuária. Revista CFMV, n.53, p.61-67, 2011.

CHAKRAVARTY, P. et al. Thermal ablation of tumor cells with antibody-functionalized single-walled carbon nanotubes. PNAS, v.105, n.25, p.8697-8702, 2008. Disponível em: <http://www. pnas.org/content/early/2008/06/16/0803557105>. Acesso em: 17 jan. 2013. doi: 10.1073/pnas.0803557105.

CHEN, R.J. et al. Noncovalent functionalization of carbon nanotubes for highly specific electronic biosensors. PNAS, v.100, n.9, p.4984-4989, 2003. Disponível em: <http://www.pnas. org/content/100/9/4984.short>. Acesso em: 26 nov. 2013. doi: 10.1073/pnas.0837064100.

CHOLPEK, J. et al. In vitro studies of carbon nanotubes biocompatibility. Carbon, v.44, n.1, p.1106-1111, 2006. Disponível em: <http://www.sciencedirect.com/science/article/pii/ S0008622305006998>. Acesso em: 17 jan. 2013. doi: 10.1016/j. carbon.2005.11.022.

FIRME, C.P.; BANDARU, P.R. Toxicity issues in the application of carbon nanotubes to biological systems. Nanomedicine: Nanotechnology, Biology and Medicine, v.6, n.2, p.245-256,
2010. Disponível em: <http://www.sciencedirect.com/science/ article/pii/S1549963409001646>. Acesso em: 03 fev. 2013. doi: 10.1016/j.nano.2009.07.003.

HADDON, R.C. Carbon nanotubes. Accounts of Chemical Research, v.35, n.12, p.997, 2002. Disponível em: <http://pubs. acs.org/toc/achre4/35/12>. Acesso em: 15 jan. 2013. doi: 10.1021/ ar020259h.

HILDER, T.A.; HILL, J.M. Probability of encapsulation of paclitaxel and doxorubicin into carbon nanotubes. Micro \& Nano letters, v.3, n.2, p.41-49, 2008. Disponível em: <http://ieeexplore. ieee.org/xpl/articleDetails.jsp?arnumber $=4560062>$. Acesso em: 21 jan. 2013. doi: 10.1049/mnl:20080008.

IANCU, C.; MOCAN, L. Advances in cancer therapy though the use of carbon nanotubes-mediated targeted hyperthermia. International Journal of Nanomedicine, v.6, p.1675-1684, 2011. Disponível em: <http://www.ncbi.nlm.nih.gov/pmc/articles/ PMC3160953/>. Acesso em: 02 fev. 2013. doi: 10.2147/IJN. S23588.

IANCU, C. et al. Enhanced laser thermal ablation for the in vitro treatment of liver cancer by specific delivery of multiwalled carbon nanotubes functionalized with human serum albumin. International Journal of Nanomedicine, v.6, p.129-141, 2011. Disponível em: <http://www.ncbi.nlm.nih.gov/pmc/articles/ PMC3026578/pdf/ijn-6-129.pdf >. Acesso em: 18 jan. 2013. doi: 10.2147/IJN.S15841.

IIJIMA, S. Helical microtubules of graphitic carbon. Nature, v.354, p.56-58, 1991. Disponível em: <http://www.nature.com/ nature/journal/v354/n6348/abs/354056a0.html>. Acesso em: 11 jan. 2013. doi: 10.1038/354056a0.

KAM, N.W.S. et al. Carbon nanotubes as intracellular transporters for proteins and DNA: investigation of the uptake mechanism and pathway. Angewandte Chemie International Edition, v.45, n.4, p.577-581, 2006. Disponível em: <http:// onlinelibrary.wiley.com/doi/10.1002/anie.200503389/ab stract; jsessionid=39B566E490D50FDC682A 72C 2 CBF CD859.f01t04>. Acesso em: 03 fev. 2013. doi: 10.1002/ anie. 200503389 .

KAM, N.W.; DAI, H. Carbon nanotubes as intracellular protein transporters: generality and biological functionality. Journal of the Americaon Chemical Society, v.126, n.16, p.6021-6026, 2005. Disponível em: <http://pubs-acs-org.ez27.periodicos.capes. gov.br/doi/abs/10.1021/ja050062v>. Acesso em: 29 jan. 2013. doi: $10.1021 / \mathrm{ja} 050062 \mathrm{v}$.

KONG, J. et al. Nanotube molecular wires as chemical sensors. Science, v.287, n.5453, p.622-625, 2000. Disponível em: <http:// www.sciencemag.org/content/287/5453/622.short>. Acesso em: 25 nov. 2013. doi: 10.1126/science.287.5453.622.

KOSTARELOS, K. et al. Cellular uptake of functionalized carbon nanotubes is independent of functional group and cell type. Nature Nanotecnology, v.2, n.2, p.108-113, 2007. Disponível em: <http://www.nature.com/nnano/journal/v2/ n2/abs/nnano.2006.209.html>. Acesso em: 15 jan. 2013. doi: 10.1038/nnano.2006.209.

KUZMA, J. Nanotechnolo in animal production - Upstream assessment of applications. Livestock Science, v.130, n.1, p.1424, 2010. Disponível em: <http://www.livestockscience.com/ 
article/S1871-1413(10)00069-7/abstract>. Acesso em: 25 nov. 2013. doi: 10.1016/j.livsci.2010.02.006.

LERNER, M. et al. Acarbon nanotube immunosensor for Salmonella. AIP Advances, v.1, n.4, p.1-8, 2011. Disponível em: <http:// scitation.aip.org/content/aip/journal/adva/1/4/10.1063/1.3658573>. Acesso em: 26 nov. 2013. doi: 10.1063/1.3658573.

LI, X. et al. Maturation of osteoblast-like SaoS2 induced by carbon nanotubes. Biomedical Materials, v.4, n.1, p.015005015013, 2009. Disponível em: <http://iopscience.iop.org/1748605X/4/1/015005/>. Acesso em: 27 jan. 2013. doi:10.1088/1748$6041 / 4 / 1 / 015005$.

LIU, Z. et al. Supramolecular chemistry on water-soluble carbon nanotubes for drug loading and delivery. ACS NANO, v.1, n.1, p.5056, 2007. Disponível em: <http://pubs.acs.org/doi/abs/10.1021/ nn700040t>. Acesso em: 25 nov. 2013. doi: 10.1021/nn700040t.

LIU, Z. et al. Carbon nanotubes in biology and medicine: in vitro and in vivo detection, imaging and drug delivery. Nano Research v.2, n.2, p.85-120, 2009. Disponível em: <http://www.ncbi.nlm. nih.gov/pmc/articles/PMC2824900/>. Acesso em: 21 jan. 2013. doi: $10.1007 / \mathrm{s} 12274-009-9009-8$.

MADANI, S.Y. et al. A new era of cancer treatment: carbon nanotubes as drug delivery tools. International Journal of Nanomedicine, v.6, p.2963-2979, 2011. Disponível em: <http:// www.dovepress.com/a-new-era-of-cancer-treatment-carbonnanotubes-as-drug-delivery-tools-peer-reviewed-article-IJN> Acesso em: 22 jan. 2013. doi: 10.2147/IJN.S16923.

MADANI, S.Y. et al. Conjugation of quantum dots on carbon nanotubes for medical diagnosis and treatment. International Journal of Nanomedicine, v.8, p.941-950, 2013. Disponível em: <http://www.ncbi.nlm.nih.gov/pmc/articles/PMC3592558/>. Acesso em: 16 abr. 2013. doi: 10.2147/IJN.S36416.

MÉNARD-MOYON, C. et al. Functionalized carbon nanotubes for probing and modulating molecular functions. Chemistry \& Biology, v.17, n.2, p.107-115, 2010. Disponível em: <http:// www.sciencedirect.com/science/article/pii/S1074552110000372>. Acesso em: 16 jan. 2013. doi: 10.1016/j.chembiol.2010.01.009.

SAITO, N. et al. Carbon nanotubes: biomaterial applications Chemical Society Reviews, v.38, n.7, p.1897-1903, 2009.
Disponível em: <http://pubs.rsc.org/en/Content/ArticleLanding/2 009/CS/b804822n\#!divAbstract>. Acesso em: 14 fev. 2013. doi: $10.1039 / \mathrm{B} 804822 \mathrm{~N}$.

SCOTT, N.R. Nanoscience in veterinary medicine. Veterinary Research Communications, v.31, Suppl.1, p.139-144, 2007. Disponível em: <http://link.springer.com/ article/10.1007\%2Fs11259-0 07-0083-7>. Acesso em: 20 abr. 2013. doi: 10.1007/s11259-007-0083-7.

SHIMIZU, M. et al. Carbon nanotubes induce bone calcification by bidirectional interaction with osteoblasts. Advanced Materials, v.24, n.16, p.2176-2185, 2012. Disponível em: <http:// onlinelibrary.wiley.com/doi/10.1002/adma.201103832/abstract>. Acesso em: 16 jan. 2013. doi: 10.1002/adma.201103832.

SITHARAMAN, B. et al. In vivo biocompatibility of ultrashort single-walled carbon nanotube/biodegradable polymer nanocomposites for bone tissue engineering. Bone, v.42, n.5, p.362-370, 2008. Disponível em: <http://www.sciencedirect.com/ science/article/pii/S8756328208001968>. Acesso em: $20 \mathrm{fev}$. 2013. doi: 10.1016/j.bone.2008.04.013.

USUI, Y. et al. Carbon nanotubes with high bone tissue compatibility and bone-formation acceleration effects . Small, v.4, n.2, p.240-246, 2008. Diponível em: <http://onlinelibrary.wiley. com/doi/10.1002/smll.200700670/stract?deniedAccessCustomi sedMessage $=\&$ userIsAuthenticated $=$ false $>$. Acesso em: $10 \mathrm{fev}$. 2013. doi: 10.1002/smll.200700670.

VEETIL, J.V.; YE, K. Tailored carbon nanotubes for tissue engineering applications. Biotechnol Prog, v.25, n.3, p.709-721, 2009. Disponível em: <http://www.ncbi.nlm.nih.gov/pmc/articles/ PMC2700190/>. Acesso em: 27 jan. 2013. doi: 10.1002/bp.165.

XU, Y. et al. Carbon-covered magnetic nanomaterials and their application for the thermolysis of cancer cells. International Journal of Nanomedicine, v.5, p.167-176, 2010. Disponível em: <http://www.ncbi.nlm.nih.gov/pmc/articles/PMC2865011/>. Acesso em: 19 jan. 2013.

YAMAMOTO, G. et al. A novel structure for carbon nanotube reinforced alumina composites withimproved mechanical properties. Nanotechnology, v.19, n.31, p.315708, 2008. Disponível em: <http://iopscience.iop.org/0957-4484/19/31/315708/>. Acesso em: 18 jan. 2013. doi: 10.1088/0957-4484/19/31/315708. 